\title{
Neu in der Allergiediagnostik: der Allergie-Chip
}

\author{
Multiallergentest ist auch mit getrocknetem Blut möglich.
}

Mit Hilfe des an der MedUni Wien mitentwickelten Allergie-Chips lassen sich frühzeitig allergische Sensibilisierungen erkennen. Dazu ist normalerweise die Blutabnahme beim Arzt nötig und eine anschließende Analyse in einem mit dem Chip ausgerüsteten Labor. In Österreich ist die Versorgung ausgezeichnet, es gibt ausreichend Laboratorien, die diesen neuen Test machen. Woanders sind es aber nur ganz wenige pro Land - die Blutproben müssen daher meistens bestens gesichert, aufwendig verpackt und gekühlt per Flugzeug zur Analyse gebracht werden. Das ist teuer und kompliziert. Nun hat ein Team der MedUni Wien rund um Studienleiter Rudolf Valenta vom Institut für Pathophysiologie und Allergieforschung nachgewiesen, dass dieser Multiallergentest mit getrocknetem Blut gleich gut funktioniert [1]. Dafür genügen wenige getrocknete Blutstropfen auf einen Streifen Whatman-Papier, dem weltweit am häufigsten verwendeten, extrem saugfähigen Blotting-Papier.

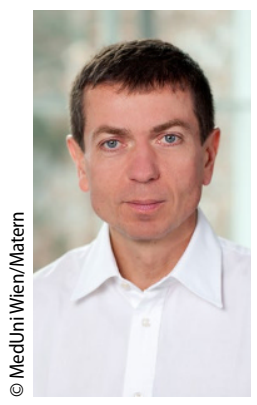

Univ.-Prof. Dr. Rudolf Valenta
Quelle: Presseaussendung der MeduniWien, 08.11.2018
Die Inspiration zu dieser Entdeckung zogen die Wiener Forscher aus den Erfahrungen beim seit über 50 Jahren eingesetzten Neugeborenen-Screening an der Universitätsklinik für Kinder- und Jugendheilkunde der MedUni Wien.,,Was hier sehr gut funktioniert, sollte doch auch mit dem an der MedUni Wien entwickelten Allergie-Screening möglich sein", so Valenta und die Erstautorin der Studie, Victoria Garib, zu ihrer These.

\section{Getrocknete Blutproben gleich aussagekräftig}

Das zentrale Ergebnis: Die getrockneten, von einem Arzt abgenommenen Blutproben zeigten das gleich Ergebnis wie eine Analyse von frischem Serum. Und das, egal wie lange die getrocknete Probe in einem Plastikumschlag bzw. mittels Brief unterwegs war und bei welcher Temperatur sie aufgetragen worden war. Garib: „Wir haben das bei
Temperaturen von plus 37 Grad ebenso gemessen wie bei minus 20 oder plus vier Grad. Das Ergebnis war immer dasselbe." Dabei wird aus dem Papier ein kleiner Teil herausgestanzt und in einem Plastikhütchen mit einer Flüssigkeit versetzt, danach werden die Antikörper in einer Zentrifuge herausgefiltert und auf den Allergie-Chip aufgetragen.

„Damit geben wir allen Ärzten und Ärztinnen weltweit die Möglichkeit, dass sie, auch wenn sie nur wenige Patienten mit Verdacht auf Allergien haben und kein Labor in der Nähe ist, einfach und schnell eine Analyse erhalten und damit den Betroffenen rasch helfen können“, ergänzt Valenta.

Auch ist es möglich, so die Wiener Forscher, die Wirksamkeit einer Immuntherapie mit den getrockneten Blutproben bzw. den daraus gewonnenen Antikörpern zu evaluieren und ein genaues Monitoring der Therapie durchzuführen.

\section{Facts \& Figures}

Die aktuelle Studie ist im Rahmen des internationalen Universitäten-Netzwerks für Molekulare Allergie und Immunologie (www.inunimai.org) entstanden, an dem derzeit zehn Länder beteiligt sind. Neben Österreich sind dies Armenien, Aserbaidschan, Weißrussland, Georgien, Kasachstan, Litauen, Russland, Ukraine und Usbekistan. Die Studie wurde vom österreichischen Wissenschaftsfonds FWF finanziell unterstützt (http://www.allergy-research-program.at/cms/).

Rudolf Valenta ist auch Mitglied des Comprehensive Cancer Center Vienna von MedUni Wien und AKH Wien.

\section{Über den Allergie-Chip}

Der Allergie-Chip, der an der MedUni Wien von der Arbeitsgruppe Valenta mitentwickelt wurde, deckt mit Hilfe von fluoreszenz-markierten Antikörpern mögliche Allergien auf. Derzeit kann das Serum auf mehr als 100 Allergene gleichzeitig getestet werden, von Apfel bis Pollen, von Gräsern, Nahrungsmittelallergenen und Bienenstich bis hin zu diversen, eigentlich harmlosen Umweltstoffen wie Hausstaub.

Vor allem bei Kindern ist die frühzeitige Allergie-Erkennung immens wichtig, um spätere chronische Erkrankungen wie etwa Asthma zu verhindern.

Der Chip gilt mittlerweile als weltweit sicherste Methode zur Früherkennung von Allergien.

\section{Literatur \\ 1. Garib V, Rigler E, Gastager F, Campana R, Dorofeeva Y, Gattinger P, Zhernov Y, Khaitov $M$, Valenta R Determination of $\lg E$ and lgG reactivity to more than 170 allergen mole- cules in paper dried blood spots". https:// doi.org/10.1016/j.jaci.2018.08.047}

Paediatr. Paedolog. Austria 2019 · 54:36 https://doi.org/10.1007/s00608019-0646-1

(c) Springer-Verlag GmbH Austria, ein Teil von Springer Nature 2019 